\title{
Nature of the bulk defects in GaAs through high-temperature quenching studies
}

\author{
C. V. Reddy, S. Fung, and C. D. Beling \\ Department of Physics, The University of Hong Kong, Pokfulam Road, Hong Kong
}

(Received 16 April 1996)

\begin{abstract}
Deep-level transient spectroscopy has been applied to $n$-type horizontal gradient freeze grown GaAs that has been subjected to thermal stressing (quenching) and varying degrees of arsenic outdiffusion during rapid thermal annealing. The concentrations and activation energies of the various deep donor levels have been monitored. As a result of the external excitations in the lattice due to the thermal stress (quenching), dramatic effects occur in the defect level structure that could be of importance to device technology. It is found that the native EL6 group of defects is nearly absent in rapid thermally annealed material, while the levels EL5 and EL8 appear with EL3 becoming a dominant level that could act as a recombination center. With the lengthening of annealing time and significant As outdiffusion, there is a general reduction of the EL2, EL3, and EL5 defect concentrations together with a complete removal of EL8. Moreover, the EL2 activation energy may be varied from 0.827 to $0.922 \mathrm{eV}$ by controlling the level of As out-diffusion. These observations are discussed in terms of the $\mathrm{As}_{\mathrm{Ga}}-\mathrm{As}_{i}$ model of the EL2 defect and the $V_{\mathrm{As}}-V_{\mathrm{Ga}}$ divacancy model for the EL6 group of defects. The EL3, EL5, EL8, and EL15 defect levels seen in samples subjected to rapid thermally quenching are attributed to the breakup of $V_{\mathrm{As}}-\mathrm{As}_{i}$ Frenkel pair defects known to be present in the as-grown material. [S0163-1829(96)01240-4]
\end{abstract}

\section{INTRODUCTION}

Gallium arsenide (GaAs) and lattice-matched GaAs/ $\mathrm{Al}_{x} \mathrm{Ga}_{1-x} \mathrm{As}$ and $\mathrm{GaAs} / \mathrm{In}_{x} \mathrm{Ga}_{1-x}$ As heterostructures are technologically very important in the fabrication of various electronic and optoelectronic devices such as high electron mobility transistors, metal-oxide-semiconductor field-effect transistors (MOSFET's), modulation-doped field-effect transistors, light-emitting diodes, lasers, etc. In GaAs MOSFETs, source and drain regions are formed by ion implanting with suitable ions. The ion-implanted region is then rapid thermal annealed (RTA) at high temperatures (around $800{ }^{\circ} \mathrm{C}$ ) for a few seconds in order to activate the dopant as well as to repair the implantation damage. ${ }^{1,2}$ Ohmic contacts to GaAs can also be prepared using RTA. ${ }^{3,4}$ This approach differs, in the high temperatures involved, from the conventional method of preparing Ohmic contacts by quartz furnace annealing in which relatively low temperatures (around $400{ }^{\circ} \mathrm{C}$ ) for longer periods of time (tens of minutes) are usually employed. The RTA approach is often preferred since it is easy and fast, and suffers from less contamination problems than the conventional methods. Moreover, arsenic outdiffusion due to high-temperature exposures can now be well controlled using capping or proximity approaches. ${ }^{1,5}$ However, little attention has been paid to the side effects of the large thermal stress on the samples due to the rapid heating and cooling in RTA. In silicon, it is well known that hightemperature processing followed by a rapid quench to room temperature results in the creation of defects, ${ }^{6}$ which may severely affect the performance of the electrical and optoelectronic devices. This is especially true in the case of lightemitting diodes and lasers for which quantum efficiency degradation and eventual device failure caused by an increasing defect state concentration may ensue. It is the purpose of the present paper to show the influence of rapid heating and cooling on the creation of additional defects, as well as to observe the changes taking place in some of the well-known bulk defects in GaAs using deep-level transient spectroscopy (DLTS).

\section{EXPERIMENTAL DETAILS}

The samples used in this study were cut from a horizontal gradient freeze (HGF) grown undoped, $n$-GaAs wafer with a concentration of the order of $10^{16} \mathrm{~cm}^{-3}$, supplied by MCP Wafer Technology Ltd., U.K. The samples were first degreased in acetone, trichloroethylene, and methanol. They were then subjected to an acid etch in $\mathrm{NH}_{4} \mathrm{OH}: \mathrm{H}_{2} \mathrm{O}_{2}: \mathrm{H}_{2} \mathrm{O}(1: 1: 5)$ for 1 min followed by an etch in $\mathrm{H}_{2} \mathrm{SO}_{4}: \mathrm{H}_{2} \mathrm{O}_{2}: \mathrm{H}_{2} \mathrm{O}(10: 1: 1)$ for $1 \mathrm{~min}$ to remove the native oxide. Finally a $10-\mathrm{min}$ rinse in deionized water followed by a blow dry in nitrogen gas left a clean surface for metallization. RTA was implemented in a vacuum thermal evaporator by resistively heating a tungsten boat on which the sample was kept with polished side down. A small piece of tin was positioned on the semipolished side which, after melting and diffusing into GaAs during the RTA cycle itself, formed the Ohmic contact. It is important to note that no second heat treatment was carried out on any of the samples used in the present study, in order to clearly observe the effect of RTA on the GaAs. The RTA of the sample was achieved by rapidly increasing the current through the boat, so that the desired temperature was reached within a few seconds. The current was reduced to zero as soon as the annealing was finished. The whole process was quick and efficient, and in this respect closely resembled conventional RTA. The temperature of the sample was monitored through a type- $K$ thermocouple. Four batches of samples (RTA Nos. 1-4) were prepared under progressively longer RTA's together with a reference sample (REF) which was prepared by conventional low-temperature quartz furnace annealing. The annealing conditions of the samples are given in Table I. Finally, 
TABLE I. Sample preparation history.

\begin{tabular}{|c|c|c|c|c|c|c|}
\hline \multirow[b]{2}{*}{ Sample } & \multirow{2}{*}{$\begin{array}{l}\text { Temp. } \\
\left({ }^{\circ} \mathrm{C}\right)\end{array}$} & \multirow{2}{*}{\multicolumn{2}{|c|}{ Time }} & \multicolumn{3}{|c|}{ Remarks } \\
\hline & & & & Thermal stress & As outdiffusion & annealing \\
\hline REF & 420 & $20 \mathrm{~m}$ & & zero & zero & $\begin{array}{l}\text { conventional } \\
\text { quartz furnace }\end{array}$ \\
\hline RTA No. 1 & 650 & 10 & $\mathrm{~s}$ & maximum & negligible & rapid \\
\hline RTA No. 2 & 600 & 30 & $\mathrm{~s}$ & medium & minimum & rapid \\
\hline RTA No. 3 & 550 & 60 & $\mathrm{~s}$ & minimum & medium & rapid \\
\hline RTA No. 4 & 550 & 120 & $\mathrm{~s}$ & negligible & maximum & rapid \\
\hline
\end{tabular}

thermally induced damage was etched from the sample surface using a standard $\mathrm{H}_{2} \mathrm{SO}_{4}: \mathrm{H}_{2} \mathrm{O}_{2}: \mathrm{H}_{2} \mathrm{O}$ solution to remove $\sim 3 \mu \mathrm{m}$ of material. Silver Schottky contacts were then thermally evaporated through a metal mask on to the front side of the sample in a vacuum of $10^{-6}$ mbar, and were not subjected to any annealing.

DLTS measurements were carried out in the constant bias method on a home-built system, whose details have been presented elsewhere. ${ }^{7}$ Carrier concentrations in all the samples have been measured using the capacitance-voltage ( $C-V$ ) method. For the samples subjected to maximal RTA treatment, considerable As outdiffusion led to the formation of deep levels that compensate for the $n$-type conductivity. In the constant bias mode of DLTS some signal distortion is expected when the free-carrier concentration becomes comparable to that of the deep levels. Since the constant capacitance DLTS technique, which avoids this distortion, was not available to us, there may be some small systematic errors in the DLTS parameters that we obtain, but these are not expected to affect the general trend of the results discussed below.

\section{RESULTS AND DISCUSSION}

The DLTS spectra taken on the heat-treated RTA samples Nos. 1 to 4 along with the REF sample, are shown in Fig. 1. In the REF sample, two major deep levels $D$ and $G$ are observed with activation energies of $0.363 \pm 0.006$ and 0.826 $\pm 0.010 \mathrm{eV}$, respectively. These two levels are the most commonly observed defects in bulk grown GaAs material, and are identified as EL6 and EL2 under the classification scheme of Martin, Mitonneau, and Mircea. ${ }^{8}$ Though the activation energy for EL6, as reported in the literature, is scattered in the range $0.33-0.37 \mathrm{eV}$, this defect level can always be recognized from its spectral shape, as seen from Fig. 1, which is characterized by a small unresolved peak (shoulder) on either side of it. ${ }^{5,9-14}$ The shoulder peaks $C$ and $E$ are resolvable from EL6 through a nonlinear curve-fitting program, and the activation energies are determined as 0.278 \pm 0.008 and $0.403 \pm 0.007 \mathrm{eV}$, which again using the Martin, Mitonneau, and Mircea classification are identified as EL7 and EL5, respectively. ${ }^{8}$ Finally, peak $F$, with an activation energy of $0.62 \pm 0.01 \mathrm{eV}$ and with a very low concentration, is identified with EL3. The corresponding Arrhenius plots are shown in Fig. 2.

Significant departures from the REF DLTS signature occur in the RTA-treated samples as shown in Fig. 1. In the case of the most rapid annealed sample RTA No. 1, apart from the appearance of two peaks $A$ and $B$, the intensity of the peaks $F$ (EL3) and $G$ (EL2) have increased dramatically. In contrast, peaks $C$ (EL7) and $D$ (EL6) have almost disappeared. Peaks $A$ and $B$, with corresponding activation energies of $0.105 \pm 0.016$ and $0.243 \pm 0.008 \mathrm{eV}$, are attributed to the electron deep levels EL15 and EL8, respectively. ${ }^{8}$ For RTA samples Nos. 1-4, in which the longer duration annealing has caused progressively more As outdiffusion, some systematic trends are noted. The first is a tendency for complete removal of peaks $A$ (EL15), $B$ (EL8), $C$ (EL7), and $D$ (EL6) from the spectra, with a resulting isolation of peak $E$ (EL5). The second is the appearance of what is commonly referred to as the broad $U$ band between the EL3 $(F)$ and

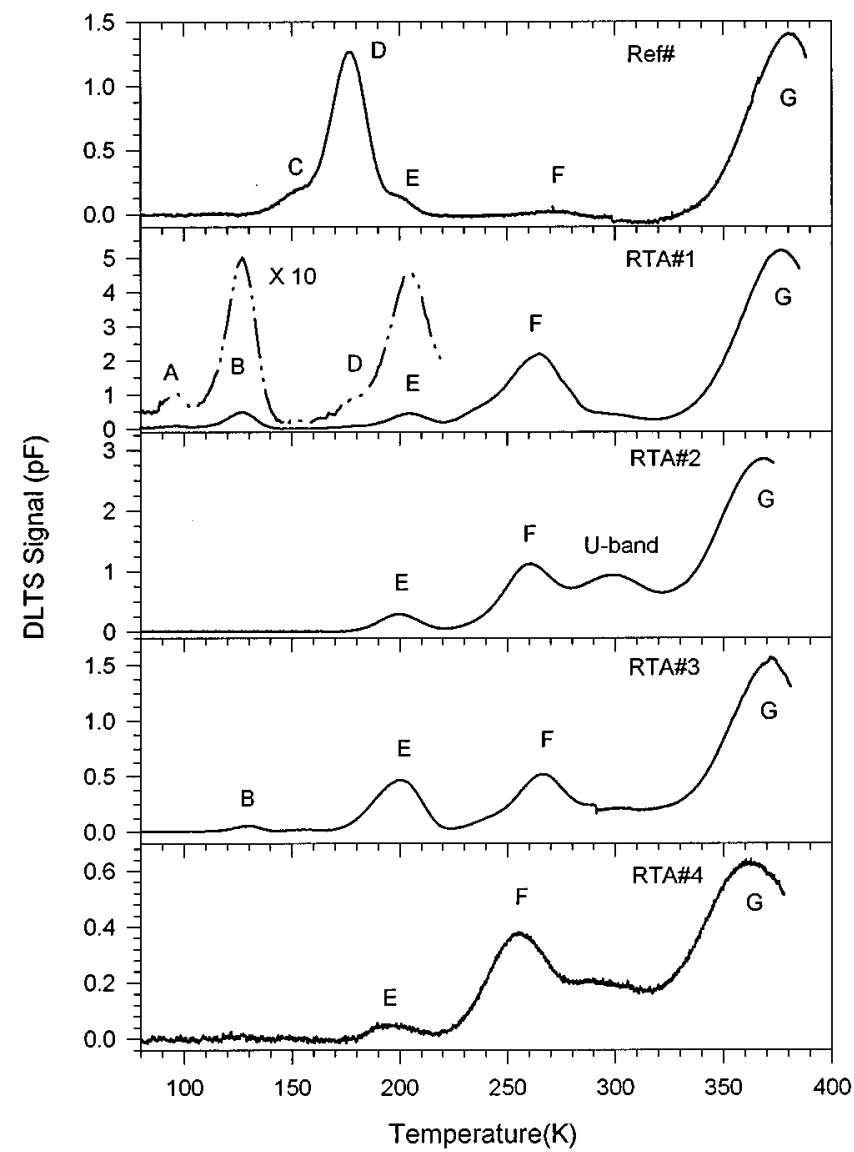

FIG. 1. The DLTS spectra recorded on $\mathrm{Ag} / n$-GaAs Schottky barriers with a rate-window time constant of $13.64 \mathrm{~ms}, V_{r}=-6 \mathrm{~V}$, $V_{p}=6 \mathrm{~V}$, a filling pulse width of $10 \mathrm{~ms}$, and quiescent capacitance of $30 \mathrm{pF}$. 


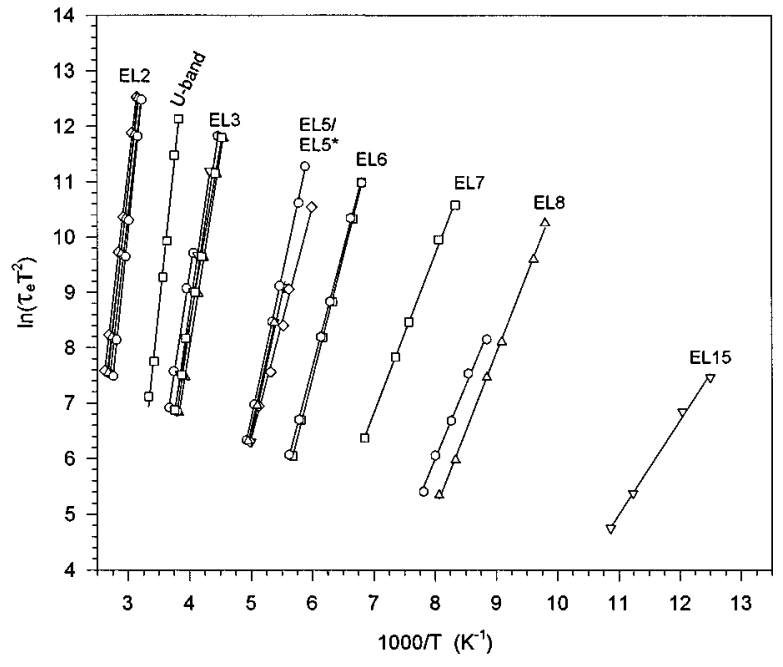

FIG. 2. The Arrhenius plots for all the defects observed in $n$-GaAs.

EL2 $(G)$ peaks. The third is the shifting of the EL2 $(G)$ peak toward lower temperatures as the sample is subjected to increased arsenic outdiffusion. The following discussion focuses on understanding these observed changes in DLTS spectra in terms of some microscopic structure models that have been proposed in the past, and where necessary additional models have been suggested.

\section{EL2 family}

The activation energy and cross section for EL2 in the RTA No. 1 sample are measured as $0.83 \pm 0.011 \mathrm{eV}$ and $3.47 \times 10^{-13} \mathrm{~cm}^{2}$, respectively, which are in good agreement with those of the REF sample as well as the earlier reported data. ${ }^{10}$ However, there is a dramatic increase in EL2 concentration of RTA No. 1 by a factor of almost 4 over the reference spectrum. As the sample is subjected to increased arsenic outdiffusion and reduced thermal stress in the sequence RTA Nos. 1-4, the EL2 peak starts shifting toward lower temperatures (Fig. 1) but at the same time, in an anomalous fashion, the electron trap lowers from 0.83 to $0.92 \mathrm{eV}$ below the conduction band. With maximum thermal stress and negligible arsenic outdiffusion, the EL2 activation energy is determined as $0.83 \mathrm{eV}$ in RTA No. 1. By allowing arsenic outdiffusion (minimum) with reduced thermal stress (RTA No. 2), the activation energy is determined as $0.843 \mathrm{eV}$. With more outdiffusion (medium) and less thermal stress (RTA No. 3), the activation energy is found as $0.876 \mathrm{eV}$. By maximizing the outdiffusion, so that compensation of the $\mathrm{GaAs}$ is at a level that almost prevents DLTS spectra being recorded, and with negligible thermal stress, the activation energy becomes $0.922 \mathrm{eV}$ (RTA No. 4), which is the highest reported so far. The respective cross-sections and concentrations are shown in Table II.

Different research groups have suggested different atomic models for EL2 in order to explain their experimental observations. All these models include the $\mathrm{As}_{\mathrm{Ga}}$ antisite in the EL2

TABLE II. Activation energies $(\mathrm{eV})$, concentrations $\left(\mathrm{cm}^{-3}\right)$, and cross sections $\left(\mathrm{cm}^{2}\right)$ of all the defects observed in $n$-GaAs. $*$ Defect labels $E 2, E 3, P 1$, and $P 2$ are from Refs. 32, 35, 36 .

\begin{tabular}{|c|c|c|c|c|c|}
\hline Defect $^{*}$ Samp & REF No. & RTA No. 1 & RTA No. 2 & RTA No. 3 & RTA No. 4 \\
\hline $\begin{array}{l}\text { Peak } A \\
(\text { EL 15) } \\
(E 2)\end{array}$ & & $\begin{array}{l}0.105 \pm 0.016 \mathrm{eV} \\
2.11 \times 10^{13} \mathrm{~cm}^{-3} \\
3.82 \times 10^{-15} \mathrm{~cm}^{2}\end{array}$ & & & \\
\hline $\begin{array}{l}\text { Peak } B \\
(\mathrm{EL} 8) \\
(E 3) \quad \mathrm{E}\end{array}$ & & $\begin{array}{l}0.243 \pm 0.008 \mathrm{eV} \\
8.81 \times 10^{14} \mathrm{~cm}^{-3} \\
1.77 \times 10^{-13} \mathrm{~cm}^{2}\end{array}$ & & $\begin{array}{l}0.228 \pm 0.010 \mathrm{eV} \\
3.04 \times 10^{13} \mathrm{~cm}^{-3} \\
1.82 \times 10^{-14} \mathrm{~cm}^{2}\end{array}$ & \\
\hline $\begin{array}{l}\text { Peak } C \\
(\text { EL7) }\end{array}$ & $\begin{array}{l}0.278 \pm 0.008 \mathrm{eV} \\
1.52 \times 10^{14} \mathrm{~cm}^{-3} \\
2.71 \times 10^{-15} \mathrm{~cm}^{2}\end{array}$ & & & & \\
\hline $\begin{array}{l}\text { Peak } D \\
\text { (EL6) }\end{array}$ & $\begin{array}{l}0.363 \pm 0.006 \mathrm{eV} \\
2.12 \times 10^{15} \mathrm{~cm}^{-3} \\
2.01 \times 10^{-13} \mathrm{~cm}^{2}\end{array}$ & $\begin{array}{l}0.375 \pm 0.006 \mathrm{eV} \\
3.07 \times 10^{13} \mathrm{~cm}^{-3} \\
5.82 \times 10^{-13} \mathrm{~cm}^{2}\end{array}$ & & $\begin{array}{l}0.362 \pm 0.013 \mathrm{eV} \\
1.31 \times 10^{15} \mathrm{~cm}^{-3} \\
1.06 \times 10^{-14} \mathrm{~cm}^{2}\end{array}$ & \\
\hline $\begin{array}{l}\text { Peak } E \\
(\text { EL5/EL5*) } \\
(P 1)\end{array}$ & $\begin{array}{l}0.403 \pm 0.007 \mathrm{eV} \\
1.52 \times 10^{14} \mathrm{~cm}^{-3} \\
1.08 \times 10^{-13} \mathrm{~cm}^{2}\end{array}$ & $\begin{array}{l}0.44 \pm 0.008 \mathrm{eV} \\
9.21 \times 10^{14} \mathrm{~cm}^{-3} \\
6.85 \times 10^{-13} \mathrm{~cm}^{2}\end{array}$ & $\begin{array}{l}0.436 \pm 0.021 \mathrm{eV} \\
4.52 \times 10^{15} \mathrm{~cm}^{-3} \\
7.61 \times 10^{-13} \mathrm{~cm}^{2}\end{array}$ & & $\begin{array}{l}0.437 \pm 0.020 \mathrm{eV} \\
2.04 \times 10^{14} \mathrm{~cm}^{-3} \\
1.78 \times 10^{-11} \mathrm{~cm}^{2}\end{array}$ \\
\hline $\begin{array}{l}\text { Peak } F \\
(\text { EL3) } \\
(P 2)\end{array}$ & $\begin{array}{c}0.62 \pm 0.01 \mathrm{eV} \\
2.52 \times 10^{13} \mathrm{~cm}^{-3} \\
1.16 \times 10^{-12} \mathrm{~cm}^{2}\end{array}$ & $\begin{array}{l}0.643 \pm 0.007 \mathrm{eV} \\
2.42 \times 10^{15} \mathrm{~cm}^{-3} \\
1.02 \times 10^{-11} \mathrm{~cm}^{2}\end{array}$ & $\begin{array}{l}0.594 \pm 0.011 \mathrm{eV} \\
1.21 \times 10^{15} \mathrm{~cm}^{-3} \\
1.53 \times 10^{-12} \mathrm{~cm}^{2}\end{array}$ & $\begin{array}{l}0.652 \pm 0.014 \mathrm{eV} \\
0.98 \times 10^{15} \mathrm{~cm}^{-3} \\
1.12 \times 10^{-11} \mathrm{~cm}^{2}\end{array}$ & $\begin{array}{l}0.554 \pm 0.008 \mathrm{eV} \\
0.52 \times 10^{15} \mathrm{~cm}^{-3} \\
1.49 \times 10^{-13} \mathrm{~cm}^{2}\end{array}$ \\
\hline $\begin{array}{l}\text { Peak } G \\
(\text { EL2) }\end{array}$ & $\begin{array}{l}0.826 \pm 0.010 \mathrm{eV} \\
3.12 \times 10^{15} \mathrm{~cm}^{-3} \\
2.02 \times 10^{-13} \mathrm{~cm}^{2}\end{array}$ & $\begin{array}{l}0.83 \pm 0.011 \mathrm{eV} \\
1.16 \times 10^{16} \mathrm{~cm}^{-3} \\
3.47 \times 10^{-13} \mathrm{~cm}^{2}\end{array}$ & $\begin{array}{l}0.843 \pm 0.009 \mathrm{eV} \\
6.02 \times 10^{15} \mathrm{~cm}^{-3} \\
8.04 \times 10^{-13} \mathrm{~cm}^{2}\end{array}$ & $\begin{array}{l}0.876 \pm 0.011 \mathrm{eV} \\
4.02 \times 10^{15} \mathrm{~cm}^{-3} \\
1.63 \times 10^{-12} \mathrm{~cm}^{2}\end{array}$ & $\begin{array}{l}0.922 \pm 0.009 \mathrm{eV} \\
2.12 \times 10^{15} \mathrm{~cm}^{-3} \\
1.78 \times 10^{-11} \mathrm{~cm}^{2}\end{array}$ \\
\hline $\begin{array}{l}\text { Carrier } \\
\text { concentration } \\
(293 \mathrm{~K})\end{array}$ & $1.1 \times 10^{16} \mathrm{~cm}^{-3}$ & $9.01 \times 10^{15} \mathrm{~cm}^{-3}$ & $5.1 \times 10^{15} \mathrm{~cm}^{-3}$ & $3.1 \times 10^{15} \mathrm{~cm}^{-3}$ & $2.9 \times 10^{15} \mathrm{~cm}^{-3}$ \\
\hline
\end{tabular}


microstructure, since this center has been clearly observed in electron paramagnetic resonance measurements with the characteristic EL2 metastability. ${ }^{15}$ Although the work of von Bardeleben et al. ${ }^{16}$ has ruled out EL2 being an isolated $\mathrm{As}_{\mathrm{Ga}}$, there is still a lack of universal agreement on the exact atomic configuration of the complex defect. Configurations that have been proposed are the arsenic interstitial $\mathrm{As}_{\mathrm{Ga}}-\mathrm{As}_{i}$ structure, ${ }^{16}$ the arsenic vacancy $\mathrm{As}_{\mathrm{Ga}}-V_{\mathrm{As}}$ structure, ${ }^{17}$ the double vacancy $\mathrm{As}_{\mathrm{Ga}}-V_{\mathrm{Ga}}-V_{\mathrm{Ga}}$ and $\mathrm{As}_{\mathrm{Ga}}-V_{\mathrm{Ga}}-V_{\mathrm{As}}$ structures, ${ }^{10,18}$ and the combination of the interstitial and double vacancy $\mathrm{As}_{\mathrm{Ga}}-\mathrm{As}_{i}-V_{\mathrm{As}}-V_{\mathrm{Ga}}$ structure. ${ }^{19}$ Except for the first of these structures, all the above models invoke at least one vacancy defect, and as such are difficult to reconcile with positron annihilation results which show little evidence for vacancy trapping in semi-insulating (SI) GaAs. ${ }^{20,21}$ Since the neutral charge state of EL2 dominates in SI GaAs at reasonable concentrations $\left(\sim 10^{16} \mathrm{~cm}^{-3}\right)$, it would be expected to see a significant degree of positron trapping if EL2 were associated with any vacancy. The other positron annihilation result that has important bearing on the EL2 structure is the observation of a vacancy in the defect's metastable configuration, ${ }^{22}$ which strongly supports the simple $\mathrm{As}_{\mathrm{Ga}} \Leftrightarrow V_{\mathrm{Ga}}+\mathrm{As}_{i}$ theory of metastability ${ }^{23}$ and significantly reduces any need to hypothesis vacancy sites within the EL2 microstructure. Based on the above arguments, the $\mathrm{As}_{\mathrm{Ga}}-\mathrm{As}_{i}$ structure is the one preferred in first addressing our results, although the possible interaction with other centers such as $V_{\text {As }}$ is also discussed for some of the RTA samples.

An explanation for the increased EL2 concentration as observed in RTA No. 1 may be forwarded as follows. Since most of the bulk GaAs is grown in As-rich conditions, it is generally accepted that there exists plenty of $\mathrm{As}_{i}$ in the lattice. ${ }^{8,24} \mathrm{~A}$ sudden thermal excitation of the lattice causes an increased $\mathrm{As}_{i}$ mobility thus effectively forming an As gas surrounding other point defects in the GaAs. Two processes then arise that lead to the production of more EL2 $\left(\mathrm{As}_{\mathrm{Ga}}-\mathrm{As}_{i}\right)$ sites. The first is that the $\mathrm{As}_{i}$ can fill a $V_{\mathrm{Ga}}$ site forming $\mathrm{As}_{\mathrm{Ga}}$, while the second is that the $\mathrm{As}_{i}$ interacts with $\mathrm{As}_{\mathrm{Ga}}$ originally present in the lattice (or formed through the $V_{\mathrm{Ga}}$ annihilation) to form the $\mathrm{As}_{\mathrm{Ga}}-\mathrm{As}_{i}$ defect. Hence we believe that thermal stress on the RTA No. 1 sample has not affected the atomic configuration of the EL2 defect, but has only created more similar defects.

The increased activation energies of EL2, and at the same time its increased electron emission rate, are not easy observations to explain. Such unusual behavior was also reported by Min, Kim, and $\mathrm{Cho}^{19}$ in the annealing of horizontal Bridgman (HB) -grown material who invoked variations in a native double vacancy model of EL2 (or one involving the $\mathrm{Si}$ impurity) to explain their observations. In the sequence of longer annealings from RTA Nos. 1-4, there is progressively larger As outdiffusion from the lattice. The effect of this is twofold, namely, a decrease in the $\mathrm{As}_{i}$ concentration and removal of As from lattice sites with the production of $V_{\mathrm{As}}$. Either or both of these effects could be responsible for transformations in the original EL2 structure. It is generally accepted that EL2 may not have a precise structure, but that because it often appears with variations in its activation energy, it consists of many closely spaced configurations of similar energy. In the $\mathrm{As}_{\mathrm{Ga}}-\mathrm{As}_{i}$ model, the family of states may simply be understood in terms of variations in the $\mathrm{As}_{\mathrm{Ga}}$ to $\mathrm{As}_{i}$ separation distance over the EL2 ensemble. It has also been pointed out ${ }^{25}$ that the presence of electron traps in close proximity $(<100 \AA)$ to the defect could drastically effect the emission rate of EL2 to the conduction band. We thus suggest that one possibility for the increased EL2 activation energy is that the mean separation of $\mathrm{As}_{\mathrm{Ga}}$ to $\mathrm{As}_{i}$ is changing as As is removed from the crystal lattice, and that this is also responsible for the increased electron emission rate. Alternatively, the presence of $V_{\mathrm{As}}$ in the proximity of the $\mathrm{As}_{\mathrm{Ga}}-\mathrm{As}_{i}$ defect may strongly influence the electron emission rate and hence the activation energy. The recent Car-Parrinello calculations of the $V_{\mathrm{As}}$ defect have shown that the $V_{\mathrm{As}}^{-}$and $V_{\mathrm{As}}^{2-}$ charge states have energy levels of 0.65 and $0.59 \mathrm{eV}$ above the valence band, respectively (activation energies of 0.85 and $0.91 \mathrm{eV}$ taking the $T=0-\mathrm{K}$ band gap as $1.5 \mathrm{eV}) .{ }^{26}$ Since the $\operatorname{EL} 2(+/ 0)$ level lies $0.75 \mathrm{eV}$ below the conduction band, ${ }^{27}$ it becomes energetically possible for a $V_{\mathrm{As}}$ site in reasonably close proximity to the $\mathrm{As}_{\mathrm{Ga}}-\mathrm{As}_{i}$ to receive an electron and place the EL2 defect in its singly ionized $(+)$ state. In this state EL2 ${ }^{+}$has an activation energy of $0.93 \mathrm{eV}$, which is in good agreement with the activation energy we observed for samples (e.g., RTA No. 4) subjected to large As outdiffusion.

The formation of the $U$ band is clearly visible as shown in Fig. 1. It has been postulated that the origin of the $U$ band is due to emission from the EL2 level via the EL6 level through a multiphonon-assisted tunneling-hopping process. ${ }^{25,28,29}$ In the RTA No. 2 sample the band is found to be narrow enough to enable a peak maximum to be obtained. An attempt to find out the activation energy for this band yielded a value of $0.89(2) \mathrm{eV}$, which is slightly higher than the EL2 activation energy measured in the same sample. This suggests that the $U$ band is a continuum of defect states closely related to the EL2 structure. Indeed, one explanation for the broad $U$ band is that the basic $\mathrm{As}_{\mathrm{Ga}}-\mathrm{As}_{i}$ (EL2) structure emits to the conduction band, but at a rate that varies according to either the number or positioning of the $\mathrm{As}_{i}$ in proximity with the antisite.

\section{EL6 group}

The sequence of deep levels seen in our REF sample as EL5, EL6, EL7 are often referred to as the EL6 group, because they occur in close proximity to each other and are nearly always present together in the as-grown material. ${ }^{9-14,19}$ Indeed there seems to be growing evidence that these three levels are not due to separate defects but different electronic states of the same atomic configuration. Recently Shiraki, Tokuda, and Sassa showed a close interaction between the EL5 and EL6 levels in bulk grown $n$-type $\mathrm{GaAs}$, the intensity of the EL5 level increasing relative to EL6 according to the filling pulse duration on the time scale of seconds. ${ }^{30}$ We have recently confirmed this EL6 to EL5 transition, and have in addition observed a similar transition of EL7 to EL6 as a function of filling pulse duration in the much faster submicrosecond time regime. These transitions are a matter of current investigation in our laboratory, and will be the subject of a future publication. For the present discussion it is sufficient to note that EL5/6/7 group is most likely a single point defect that has a number of stable configurations that differ according to the electron occupancy. 
There is at present no common consensus on the defect structure responsible for the EL5/6/7 group. Yakimova, Paskova, and Hardalov recently gave convincing evidence that a possible candidate for the origin of the EL5 level is a complex defect involving $V_{\mathrm{Ga}}-\mathrm{As}_{i}$. ${ }^{31}$ The EL5 defect has also been tentatively identified with the Frenkel pair $V_{\mathrm{As}}-\mathrm{As}_{i}$ defect $E 3$ found in electron-irradiated material. ${ }^{8,32}$ On the other hand, Fang, Schlesinger, and Milnes suggested that a possible candidate for the EL6 defect is the $V_{\mathrm{Ga}}-V_{\mathrm{As}}$ divacancy with a possible interaction of $\mathrm{As}_{i} \cdot{ }^{5}$ Pöykkö, Poska, and Nieminen recently pointed out that such a divacancy pairing is very likely due to the mutual Coulomb attraction between $V_{\mathrm{Ga}}^{3-}$ and $V_{\mathrm{As}}^{+}$when the Fermi level is close to midgap during crystal growth. ${ }^{33}$ These authors carried out a detailed Car-Parrinello analysis on the relaxation of the $V_{\mathrm{Ga}}-V_{\mathrm{As}}$, showing that, in all four charge states $(2-, 1-, 0$, and $1+)$ of the defect, the electron energy states reside close to the valence band. It is thus unlikely that the isolated $V_{\mathrm{Ga}}-V_{\mathrm{As}}$ complex is to be associated with the EL6 group although configurations such as $V_{\mathrm{Ga}^{-}}-V_{\mathrm{As}}-\mathrm{As}_{i}$ (Ref. 5) and $V_{\mathrm{Ga}}-V_{\mathrm{As}}-\mathrm{As}_{\mathrm{Ga}}$ cannot be ruled out.

With reference to the RTA No. 1 spectrum, it may be seen that alongside the formation of the new defects (peaks $A$ and $B)$, the EL6 peak $(D)$ has almost been annealed out. Careful analysis of the spectrum, however, shows that there still exists a peak $D$ with an activation energy $0.375(6) \mathrm{eV}$, which may be attributed to the EL6 defect. On either side of it, there are two fully developed peaks $B$ and $E$ with corresponding activation energies $0.243(8)$ and $0.440(8) \mathrm{eV}$, which have been identified as EL8 and EL5, respectively. This spectral change could be understood as a result of some transformation or dissociation of the EL6 defect during the higher-temperature RTA anneals and resulting in the formation of EL8 and EL5 defects. Such a dissociation may be forwarded along the lines proposed by Fang, Schlesinger, and Milnes, whereby the $V_{\mathrm{Ga}}-V_{\mathrm{As}}$ complex is seen as being destroyed under annealing with the resultant formation of other stable complexes. ${ }^{5}$ If the EL5/6/7 structure is due to the interaction of an $\mathrm{As}_{i}$ (or $\mathrm{As}_{\mathrm{Ga}}$ ) with the divacancy $V_{\mathrm{Ga}}-V_{\mathrm{As}}$, then, on dissociation structures such as $V_{\mathrm{Ga}}-\mathrm{As}_{i}\left(\mathrm{As}_{\mathrm{Ga}}\right)$ and $V_{\mathrm{As}}-\mathrm{As}_{i}\left(\mathrm{As}_{\mathrm{Ga}}\right)$ could result giving rise to EL5 and EL8 peaks, respectively. An initial criticism of such a dissociation model is that one would not expect to have the same EL5 level characterizing the initial (preanneal) final (postanneal) defects. However, a close inspection of the activation energies shows that the EL5 level after anneal has an energy close to $0.440(8) \mathrm{eV}$ rather than $0.403(7) \mathrm{eV}$, indicating that some structural change has indeed occurred. The rapid thermal anneal has produced some new level, EL5* (peak $E$ in RTA Nos. 1-4) say, that to our knowledge has not hitherto been reported, that has in the past been confused with EL5, and that has an ionization level close to $0.44 \mathrm{eV}$.

The dissociation model of EL6 is not the only model for explaining the appearance of the EL8 and EL5* deep levels. Indeed, the model has one significant drawback, which is that it is hard to explain how the separation of the $V_{\mathrm{As}}$ and $V_{\mathrm{Ga}}$ sites takes place at annealing temperatures of 550$650{ }^{\circ} \mathrm{C}$, since such a transmutation would require the unlikely hopping of at least one of the two vacancies to a nearest-neighbor sublattice site. ${ }^{34}$ A more likely explanation for the appearance of EL8 and EL5* levels in the RTA samples can be based upon an entirely different picture that is shown schematically in Fig. 3. As discussed in the sections below, there is good evidence to associate both EL8 and EL5* with a common precursor state, namely, the loosely associated $V_{\mathrm{As}}-\mathrm{As}_{i}$ Frenkel pair-type defect that gives rise to the $E 1$ and $E 2$ levels seen in DLTS studies of irradiated materials, ${ }^{32,35,36}$ and by positron annihilation studies in $n$-type as-grown material. ${ }^{20,37}$ Such levels are seen in fast annealed samples because there has been insufficient time for either self-annihilation of the $V_{\mathrm{As}}-\mathrm{As}_{i}$ associated pairs (EL8) or the annihilation of isolated $V_{\mathrm{As}}^{n-}\left(\mathrm{EL} 5^{*}\right)$ with the diffusing $\mathrm{As}_{i}$ gas. On the other hand, with the much longer times available under furnace annealing, the EL8 and EL5 defects are annihilated, and $\mathrm{As}_{i}$ migrating through the lattice has the opportunity to interact with as-grown $V_{\mathrm{Ga}}-V_{\mathrm{As}}$ divacancies to form complexes such as $\mathrm{As}_{\mathrm{Ga}}+V_{\mathrm{As}}, \mathrm{As}_{\mathrm{Ga}}+V_{\mathrm{As}}+\mathrm{As}_{i}$, $V_{\mathrm{Ga}}+\mathrm{As}_{i}$, and $V_{\mathrm{Ga}}+V_{\mathrm{As}}+\mathrm{As}_{i}$. It is through one or more of these complexes that we envisage the EL6 group of deep levels arising.

In Fig. 4, the concentration of the EL5* level is shown plotted against the degree of As outdiffusion. It is noted that there is a general decrease in the concentration which parallels the decrease in EL2 concentration. A similar correlation between the EL2 and EL5 peak intensities was observed by Yakimova, Paskova, and Hardalov under increasing levels of $\mathrm{Sb}$ doping, and points to a common component in the structure of these defects. ${ }^{31}$ If we take the dissociation model of EL6 in which EL5* is taken as the $V_{\mathrm{Ga}^{-}}-\mathrm{As}_{i}\left(\mathrm{As}_{\mathrm{Ga}}\right)$ structure, then this common component in EL5 and EL2 could either be $\mathrm{As}_{i}$ or $\mathrm{As}_{\mathrm{Ga}}$ (the association $V_{\mathrm{Ga}}-\mathrm{As}_{i}$ being the more likely, owing to the much higher $\mathrm{As}_{i}$ mobility). If, on the other hand, we adopt the view that EL6 forms only on longtime-scale annealing of GaAs (Fig. 3), with EL5* being related to some $V_{\mathrm{As}}$-related state then no common component is readily apparent, although the reduced intensity of EL5* would be indicative of the recombination of $V_{\mathrm{As}}$ with $\mathrm{As}_{i}$.

\section{EL3 defect}

Another change observed in the RTA No. 1 deep-level spectrum when compared to the reference is the change in intensity of EL3, which has increased by two orders of magnitude. Little attention was paid by previous workers in considering the atomic nature of this defect probably as a result of its appearance in low concentrations in conventionally annealed samples. In the present work, we give the EL3 level some consideration, since with its relatively large concentration $\left(\sim 10^{15} \mathrm{~cm}^{-3}\right)$ and close proximity to the midgap, the possibility exists that the defect site responsible for EL3 could form an important recombination center.

Min, Kim, and Cho, in their RTA studies of HB-grown GaAs also observed that the EL3 level was somewhat enhanced under annealing. ${ }^{19}$ The enhancements we see, however, in our HGF material seem to be significantly larger. Whether or not this difference is due to the different growth processes or whether it results from differences in the RTA treatment is not clear, and further research is required to identify the factors involved in producing EL3.

We speculate here that EL3 could be due to a $V_{\text {As }}$-related defect in a configuration close to its isolated state. The isolated $V_{\mathrm{As}}$ defect is expected to occur in GaAs in at least four 


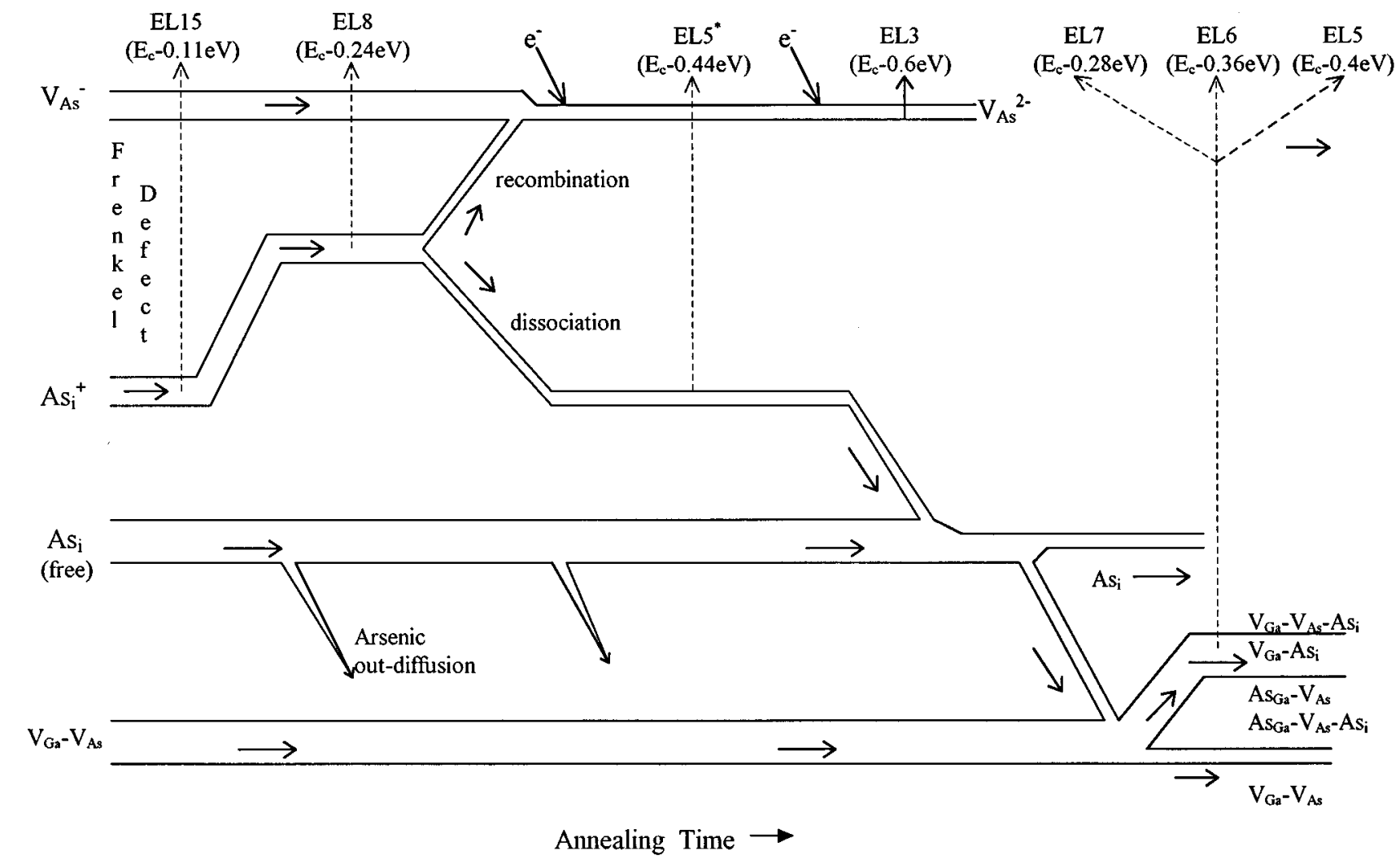

FIG. 3. Showing recombination and dissociation of Frenkel $V_{\mathrm{As}}-\mathrm{As}_{i}$ pair defects, together with $\mathrm{As}_{i}$ interaction with a $V_{\mathrm{Ga}}-V_{\mathrm{As}}$ double vacancy to produce possible a EL5/6/7 group of defects through a complex defect, such as $\mathrm{As}_{\mathrm{Ga}}-V_{\mathrm{As}}, \mathrm{As}_{\mathrm{Ga}}-V_{\mathrm{As}}-\mathrm{As}_{i}, V_{\mathrm{Ga}}-\mathrm{As}_{i}$, and $V_{\mathrm{Ga}}-V_{\mathrm{As}^{-}}-\mathrm{As}_{i}$.

charge states $(1+, 0,1-$, and $2-)$, and recent Car-Parrinello calculations place the ionization levels $(0 /+),(-/ 0)$, and $(2-/ 1-)$ at $E_{c}-90 \mathrm{meV}, E_{c}-0.85 \mathrm{eV}$, and $E_{c}-0.91 \mathrm{eV}$, respectively. ${ }^{33}$ Thus for $n$-type material it is expected that the stable configuration of the $V_{\text {As }}$ defect will be the $V_{\text {As }}^{2-}$ state. Positron annihilation studies of $n$-type GaAs have revealed the presence of $V_{\text {As }}$-related defects in high concentrations $\left(10^{16}-10^{17} \mathrm{~cm}^{-3}\right)$ having ionization levels $(0 /+)$ at $E_{c}-140 \mathrm{meV}$ and $(-/ 0)$ at $E_{c}-30 \mathrm{meV},{ }^{20}$ results that contradict theory if these levels are to be associated with the isolated $V_{\mathrm{As}}$. Recently, however, Saarinen et al. ${ }^{37}$ pointed out that the ionization levels seen by positron annihilation coincide almost exactly with the $E 1$ and $E 2$ levels seen by DLTS in electron-irradiated GaAs, ${ }^{35,36}$ and which are associated with different electron occupancy of the same $V_{\mathrm{As}}-\mathrm{As}_{i}$ Frenkel pair defect. ${ }^{32}$ Under rapid thermal annealing, the mobility of the $\mathrm{As}_{i}$ increases dramatically causing both the selfannihilation of the $E 1$ and $E 2$ levels by $V_{\mathrm{As}}-\mathrm{As}_{i}$ recombination and, at the same time, some breaking of the Frenkel pair bonds with the resulting liberation of $V_{\text {As }}^{-}$sites which in $n$-type material would gain electrons to from $V_{\text {As }}^{n-}$. This picture agrees well with the positron annihilation data, in which only a partial annealing of the $V_{\mathrm{As}}$-related site occurs in the temperature range $(550-650 \mathrm{~K}),{ }^{37}$ with the vacancy signal persisting to much higher temperatures. ${ }^{38}$ It also agrees with DLTS data in which the E1/E2 structure anneals out around $500 \mathrm{~K} .{ }^{39}$ Here we postulate (see Fig. 3) that the RTA process differs from the furnace anneal, in that in the former the fast cooling of the sample freezes in the $\mathrm{As}_{i}{ }^{+}$at some distance from the $V_{\mathrm{As}}^{n-}$, while in the latter there is sufficient time with slower cooling to allow most $V_{\mathrm{As}}^{n-}$ to recombine with $\mathrm{As}_{i}$. This would explain why a more intense EL3 peak is seen in RTA-treated rather than furnace-annealed samples.

It is of interest to note that DLTS studies made on electron-irradiated materials subjected to above-500 K annealing reveal the presence of three new deep levels $P 1, P 2$ and $P 3$ (ionization levels $E_{c}-0.36, E_{c}-0.5$, and $E_{C}-0.72$ $\mathrm{eV}$, respectively) that are most probably the remnant of primary Frenkel-pair-type defects that have escaped self-annihilation. ${ }^{36}$ In an almost identical fashion to our DLTS spectra, the $P 1$ and $P 2$ peaks occur at temperatures of 200 and $280 \mathrm{~K}$ using an emission rate of $70 \mathrm{~s}^{-1}$ (almost identical to the $73 \mathrm{~s}^{-1}$ used in obtaining our spectra-Fig. 1) making their identification as EL5* and EL3 fairly certain. With these deep levels being associated with the breakup of the Frenkel pair $\left(V_{\mathrm{As}}-\mathrm{As}_{i}\right)$, it is highly plausible that they are connected with the isolated $V_{\text {As }}$. This being the case, it is necessary to address the question as to why the ionization energy levels are in disagreement from those predicted by the Car-Parrinello theory of the isolated $V_{\mathrm{As}}$ ? While there could be some missing factor in the theoretical modeling, it is quite likely that some coupling to the $\mathrm{As}_{i}$ still exists, perturbing the $V_{\mathrm{As}}$ electronic states. On the other hand, the $V_{\mathrm{As}}$ defect could exist in the three-, four-, and five-charge states, and as yet there exist no calculations that would suggest that such states may not have ionization levels in the upper half of the band gap, which could give rise to the EL3 level.

From Fig. 4, it is noted that the EL3 concentration also shows a slight reduction with increased As outdiffusion in a 


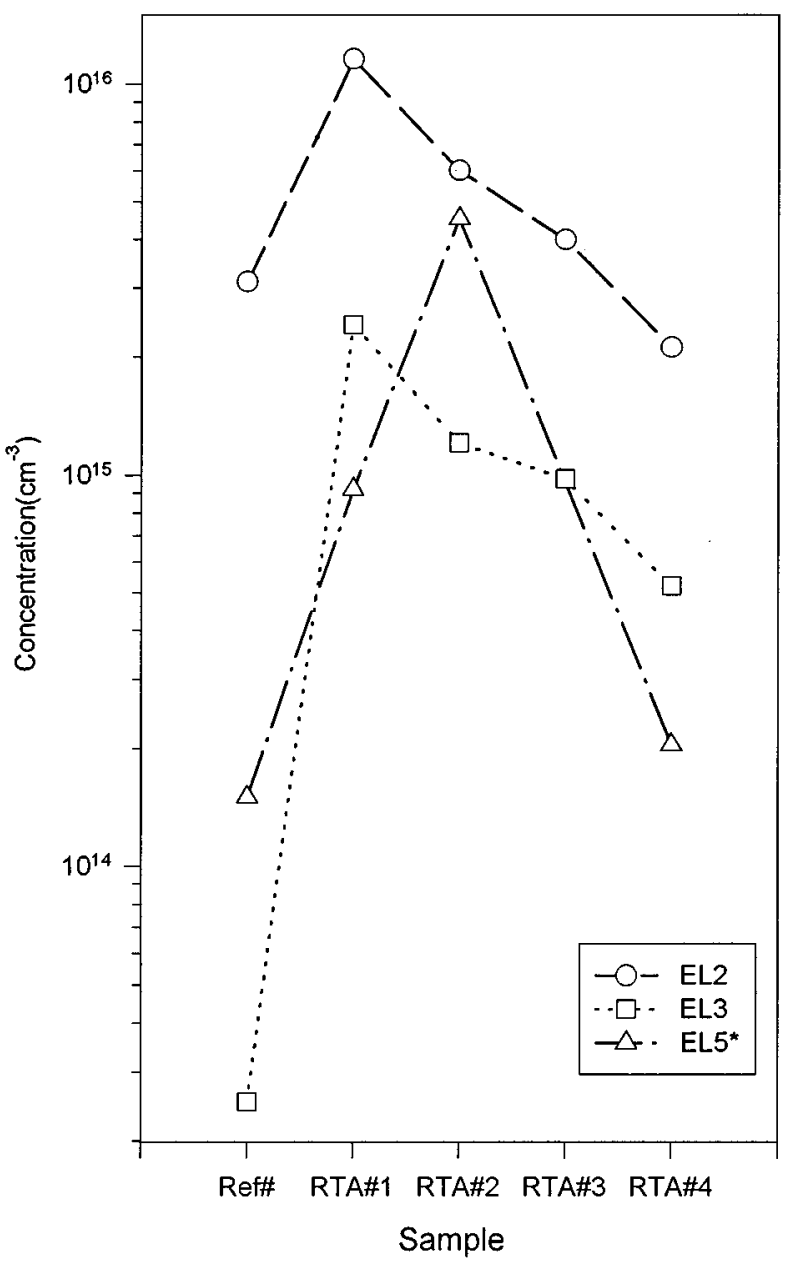

FIG. 4. EL2, EL3, and EL5* defect concentrations plotted as a function of arsenic outdiffusion.

parallel fashion to EL2 and EL5*. On the above model for EL3, providing some long distance association of the isolated $V_{\mathrm{As}}$ site is made with $\mathrm{As}_{i}$, the reduction in concentration could still be due to the reduced concentration of $\mathrm{As}_{i}$ produced on As outdiffusion. On the other hand, if EL3 is really related to an isolated $V_{\mathrm{As}}$ site, then it is more plausible that we are witnessing the diffusive recombination of $\mathrm{As}_{i}$ by a $V_{\mathrm{As}}$ site in the reduced EL3 concentration.

\section{EL8 and EL15 defects}

Finally, we turn our discussion to a consideration of the defect levels EL8 and EL15 that are seen clearly in the RTA sample No. 1 and to some lesser extent in the RTA sample No. 3. These deep levels are not present in the furnaceannealed REF sample. The measured activation energies of the levels EL8 and EL15 coincide with the levels E3 and $E 2$, respectively, observed in electron-irradiated material ${ }^{36}$ which have since been convincingly linked to Frenkel pair $V_{\mathrm{As}}-\mathrm{As}_{i}$ atomic structures of different $V_{\mathrm{As}}$ to $\mathrm{As}_{i}$ separations. ${ }^{32}$ Making such an identification, the question then arises as to why it is only in RTA samples subjected to maximal stress that EL8 (E3) and EL15 (E2) are seen. In a similar manner to the discussion on the formation of the EL3 defect (see above), thermal excitation of the lattice is expected to cause the $\mathrm{As}_{i}$ to become mobile and to thus anni- hilate with As vacancy sites. The only difference is that the process is expected to be faster since the $V_{\mathrm{As}}^{-} \mathrm{As}_{i}{ }^{+}$Frenkel pairs are closely associated and will Coulombically diffuse together. Rapid thermal quenching, provided it is carried out fast enough, may be expected to freeze in these EL8 and EL15 defects, and thus explain the fact that, in two of our RTA samples, these deep levels have been observed.

\section{CONCLUSIONS}

We have carried out a systematic study of deep-level defects introduced into $n$-type GaAs as a result of rapid thermal annealing. Our main observation is that the types of defect introduced and their concentrations differ significantly from those formed in conventional furnace annealing. It is found that the EL2 concentration is generally larger on RTA samples, and that the ionization energy of this deep donor can be significantly affected if significant As outdiffusion is allowed. These effects can be interpreted on the $\mathrm{As}_{\mathrm{Ga}}-\mathrm{As}_{i}$ atomic model of EL2 with some possible long-range coupling to the As vacancy being possible. Another significant difference is that the standard EL5/6/7 group of defects seen in furnace annealed GaAs is almost entirely missing in the RTA samples. Instead, other defects such as EL15, EL8 and EL5* are seen together with a dramatic increase in the intensity of EL3. We have discussed this result first in terms of the EL6 defect being associated with a $V_{\mathrm{Ga}}{ }^{-} V_{\mathrm{As}}$ divacancy complex which is considered to undergo some dissociation. We also forward another possible and perhaps more likely explanation for what may be just an 'apparent' annealing out of EL6. In this model we associate the EL6 defect group to a structure that has the as-grown $V_{\mathrm{Ga}}-V_{\mathrm{As}}$ divacancy as a precursor, and suggest that whatever the exact nature of this structure is, it has insufficient time to form in the RTA samples. In contrast, EL15, EL8, EL5*, and EL3 are seen in RTA samples because they have had insufficient time to anneal out. Defects EL15 and EL8 are associated with $V_{\mathrm{As}^{-}}-\mathrm{As}_{i}$ pairs which are seen as primary defects in electron-beamirradiated GaAs. These defects which positron annihilation studies show to be present in abundance in as-grown $n$-type GaAs anneal out easily, as they are subject to fast Coulombic self-recombination and as such are seen mainly in very fast thermal anneals. EL5* and EL3 defects, on the other hand, are seen as remnants of native $V_{\mathrm{As}^{-}}-\mathrm{As}_{i}$ pairs that have undergone some dissociation in the annealing process. The EL3 level could be some ionization level of an isolated As vacancy.

The present work indicates that, experimentally, future annealing kinetic studies dealing with time regimes between those of the present rapid thermal anneals and conventional furnace annealing may be able to distinguish between the two models discussed for EL6. However, such studies are complicated by the As outdiffusion from the sample, which occurs at RTA temperatures of $600{ }^{\circ} \mathrm{C}$ and above, and which leads to an increased concentration of deep-levels, a reduced carrier concentration, and the breakdown of the DLTS technique. Future annealing kinetic studies that would involve either monitoring the As outdiffusion, or controlling the outdiffusion with $\mathrm{Si}_{3} \mathrm{~N}_{4}$ capping, may be expected to elucidate some of the present uncertainties regarding the atomic struc- 
ture of the EL6, EL2 and related defects. Moreover, EL3 is present in sufficient concentration $\left(\sim 10^{15} \mathrm{~cm}^{-3}\right)$ to make correlated DLTS-positron annihilation studies of this defect possible in the future, thus checking whether it is really $V_{\text {As }}$ related. On the theoretical front, it is clear that further progress in understanding the point defects in GaAs could be made if Car-Parrinello ionization energy calculations existed for a wider range of possible defect configurations.
${ }^{1}$ G. Eftekhari, Semicond. Sci. Technol. 10, 1408 (1995).

${ }^{2}$ B. Tell, K. F. Brown-Goebeler, and C. L. Cheng, Appl. Phys. Lett. 52, 299 (1988).

${ }^{3}$ S. L. Wright, R. F. Marks, S. Tiwari, T. N. Jackson, and H. Baratte, Appl. Phys. Lett. 49, 1545 (1986).

${ }^{4}$ D. C. Look, Electrical Characterisation of GaAs Materials and Devices, 1st ed. (Wiley, New York, 1988), pp. 36 and 37.

${ }^{5}$ Z.-Q. Fang, T. E. Schlesinger, and A. G. Milnes, J. Appl. Phys. 61, 5047 (1987).

${ }^{6}$ H. Indusekhar and V. Kumar, Phys. Status Solidi A 95, 269 (1986).

${ }^{7}$ C. V. Reddy, S. Fung, and C. D. Beling, Rev. Sci. Instrum. 67, 257 (1996).

${ }^{8}$ G. M. Martin, A. Mitonneau, and A. Mircea, Electron. Lett. 13, 191 (1977).

${ }^{9}$ A. Yahata and M. Nakajima, Jpn. J. Appl. Phys. 23, L313 (1984).

${ }^{10}$ M. G. Lupo, A. Cola, L. Vasanelli, and A. Valentini, Phys. Status Solidi A 124, 473 (1991).

${ }^{11}$ F. D. Auret, A. W. R. Leitch, and J. S. Vermaak, J. Appl. Phys. 59, 158 (1986).

${ }^{12}$ A. Christou, W. T. Anderson, Jr., and H. M. Day, Solid-State Electron. 28, 329 (1985).

${ }^{13}$ S. J. Pearton, J. Appl. Phys. 53, 4509 (1982).

${ }^{14}$ H. Y. Cho, E. K. Kim, S.-K. Min, J. B. Kim, and J. Jang, Appl. Phys. Lett. 53, 856 (1988).

${ }^{15}$ E. R. Weber, H. Ennon, U. Kaufmann, J. Windscheif, J. Schneider, and T. Wosinski, J. Appl. Phys. 53, 6140 (1982).

${ }^{16}$ H. J. von Bardeleben, D. Stiévenard, D. Deresmes, A. Huber, and J. C. Bourgoin, Phys. Rev. B 34, 7192 (1986).

${ }^{17}$ G. A. Baraff and M. Schlüter, Phys. Rev. Lett. 55, 2340 (1985).

${ }^{18}$ J. F. Wager and J. A. Van Vechten, Phys. Rev. B 35, 2330 (1987).

${ }^{19}$ S.-K. Min, E. K. Kim, and H. Y. Cho, J. Appl. Phys. 63, 4422 (1988).

${ }^{20}$ K. Saarinen, P. Hautojärvi, P. Lanki, and C. Corbel, Phys. Rev. B 44, 10585 (1991).
${ }^{21}$ K. Saarinen, S. Kuisma, P. Hautojärvi, C. Corbel, and C. LeBerre, Phys. Rev. Lett. 70, 2794 (1993).

${ }^{22}$ R. Krause, K. Saarinen, P. Hautojärvi, A. Polity, G. Gärtner, and C. Corbel, Phys. Rev. Lett. 65, 3329 (1990).

${ }^{23}$ J. Dabrowski and M. Scheffler, Phys. Rev. B 40, 10391 (1989).

${ }^{24}$ J. C. Bourgoin, H. J. von Bardeleben, and D. Stiévenard, J. Appl. Phys. 64, R65 (1988)

${ }^{25}$ G. M. Martin, E. Estéve, P. Langlade, and S. Makram-Ebeid, J. Appl. Phys. 56, 2655 (1984).

${ }^{26}$ K. Laasonen, R. M. Nieminen, and M. J. Puska, Phys. Rev. B 45, 4122 (1992)

${ }^{27}$ M. Kaminska and E. R. Weber, in Imperfections in III-V Materials, edited by E. R. Weber Semiconductors and Semimetals Vol. 38 (Academic, Boston, 1993), p. 59.

${ }^{28}$ G. M. Martin, and S. Makram-Ebeid, Physica 116B, 371 (1983).

${ }^{29}$ J. Samitier, J. R. Morante, L. Giraudet, and S. Gourrier, Appl. Phys. Lett. 48, 1138 (1986).

${ }^{30}$ H. Shiraki, Y. Tokuda, and K. Sassa, in Defect- and ImpurityEngineered Semiconductors and Devices, edited by S. Ashok, J. Chevallier, I. Akasaki, N. M. Johnson, and C. L. Sapori, MRS Symposium Proceedings No. 378 (Materials Research Society, Pittsburgh, 1995), p. 935.

${ }^{31}$ R. Yakimova, T. Paskova, and Ch. Hardalov, J. Appl. Phys. 74, 6170 (1993).

${ }^{32}$ D. Stiévenard, X. Boddaert, J. C. Bourgoin, and H. J. von Bardeleben, Phys. Rev. B 41, 5271 (1990).

${ }^{33}$ S. Pöykkö, M. J. Puska, and R. M. Nieminen, Phys. Rev. B 53, 3813 (1996).

${ }^{34}$ N. Arnold, R. Schmittk, and K. Heine, J. Phys. D 17, 443 (1984).

${ }^{35}$ D. Pons, A. Mircea, and J. C. Bourgoin, J. Appl. Phys. 51, 4150 (1980).

${ }^{36}$ D. Pons and J. C. Bourgoin, J. Phys. C 18, 3839 (1985).

${ }^{37}$ K. Saarinen, A. P. Seitsonen, P. Hautojärvi, and C. Corbel, Phys. Rev. B 52, 10932 (1995).

${ }^{38}$ G. Dlubek and R. Krause, Phys. Status Solidi A 102, 443 (1987).

${ }^{39}$ D. V. Lang, R. A. Logan, and L. C. Kimmerling, Phys. Rev. B 15, 4874 (1977). 